\title{
"Babies know the facts about folic": A behavioural change campaign utilising digital and social media
}

\author{
T. Flaherty, A.F. McGloin, M. Faughnan, C. Foley-Nolan and V. Dwyer \\ safefood, Block B, Abbey Court, Lower Abbey Street, Dublin 1, Ireland
}

Ireland (ROI) and Northern Ireland (NI) have high prevalence rates of Neural Tube Defects (NTD's) and evidence suggest these increased in recent years ${ }^{(1)}$. Folic acid supplementation prevents $72 \%$ of NTDs and it is recommended that women of childbearing age take a $400 \mu \mathrm{g}$ daily folic acid supplement for 12 weeks pre conception until the end of the first trimester ${ }^{(2)}$. Although women know folic acid's function in relation to preventing NTDs, approximately 1 in 5 on the island of Ireland (IOI) report taking folic acid before pregnancy $^{(3)}$. These low consumption figures appear to be as a result of the misconceptions women have in relation to folic acid, ${ }^{(4)}$ which create barriers for behavioural change.

To address the increasing rates of NTDs and the behavioural barriers to taking folic acid supplements, safefood launched a campaign in July, 2015. The campaign entitled 'Babies Know the Facts about Folic' was carried out via digital and social media marketing, but also included public relations and stakeholder engagement. Michie et al.'s (2011) taxonomy of behavioural change was used to identify a number of techniques deemed appropriate for this campaign ${ }^{(5)}$.

With approximately $50 \%$ of pregnancies unplanned, this campaign targeted all women of a childbearing age who are sexually active and could become pregnant, irrespective of whether they were planning a pregnancy or not.

To assess behavioural change an online survey was conducted pre campaign $(n=656)$ and post campaign $(n=738)$ in women aged 18-50. The data was statistically analysed using SPSS using a chi-square test for independence. In home face-to-face interviews were also carried out among a nationally representative sample of females $(n=424)$ three months after the campaign. Behavioural change was also measured using sales figures from participating pharmacies, retailers and manufacturers.

The online research indicated that prior to the campaign $26.4 \%$ of women believed that all sexually active women who could potentially become pregnant should ensure they are taking folic acid supplements. This increased to 74.8 \% post campaign $(\mathrm{p}=.000)$. The proportion of women who routinely took folic acid even though they weren't planning a pregnancy rose over the course of the campaign from $7.3 \%$ to $14.2 \%$ indicating an increase of $6.9 \%(\mathrm{p}=.000)$. Results from the in home interviews also indicated an increase, rising from $30 \%$ in 2014 to $36 \%$ in 2016 in the number of females who take folic acid supplements. Folic acid supplement sales increases by $26 \%$ on average from the same period in 2014 .

These results indicate that the campaign was successful in changing individual's knowledge, attitudes and behaviour in relation to folic acid supplements and highlight the effectiveness of using social and digital media for health behavioural change.

1. McDonnell R. Epidemiology of Neural Tube Defects in Ireland. In: National meeting on Neural Tube Defects; 2013; George's Hall, Dublin Castle, Dublin.

2. EUROCAT (2007) Survey of folic acid policy and practice in European Countries Northern Ireland. http://www.eurocat-network.eu/content/ Special-Report-NTD-Survey-of-FA-2007.pdf (accessed September 2015).

3. Cawley S, Mullaney L, McKeating A et al. An analysis of folic acid supplementation in women presenting for antenatal care. $J$ Public Health $(O x f)$. Published online: 1 March 2015. doi:10.1093/pubmed/fdv019.

4. Faughnan MF, Cahill D, Burgoyne L, et al. (2009) Barriers and facilitators to taking folic acid supplements among women aged 18-30 years. Proc Nutr Soc 68(OCE3):E149.

5. Michie S, Ashford S, Sniehotta FF et al. (2011) A refined taxonomy of behaviour change techniques to help people change their physical activity and healthy eating behaviours: The CALO-RE taxonomy. Psychol Health 26, 1479-1498. 